\title{
CNS-directed gene therapy for lysosomal storage diseases
}

\author{
Mark S Sands ${ }^{1}$ and Mark E Haskins ${ }^{2}$ \\ ${ }^{1}$ Department of Internal Medicine and Department of Genetics, Washington University School of \\ Medicine, St. Louis, MO, USA \\ 2Section of Medical Genetics and Laboratory of Pathology, School of Veterinary Medicine, \\ University of Pennsylvania, Philadelphia, PA, USA
}

\begin{abstract}
Lysosomal storage diseases (LSDs) are a group of inherited metabolic disorders usually caused by deficient activity of a single lysosomal enzyme. As most lysosomal enzymes are ubiquitously expressed, a deficiency in a single enzyme can affect multiple organ systems, including the central nervous system (CNS). At least 75\% of all LSDs have a significant CNS component. Approaches such as bone marrow transplantation (BMT) or enzyme replacement therapy (ERT) can effectively treat the systemic disease associated with LSDs in some patients. However, CNS disease remains a major challenge. Gene therapy represents a promising approach for the treatment of CNS disease as it has the potential to provide a permanent source of the deficient enzyme. Direct intracranial injection of viral gene transfer vectors has resulted in reduced lysosomal storage and functional improvement in certain small (rodent) and large (canine and feline) animal models of LSDs. The addition of protein transduction domains (PTDs) to the recombinant enzymes increased the distribution of enzyme and the extent of correction. Therapeutic levels of lysosomal enzymes can also be delivered to distant sites in the brain by anterograde and retrograde axonal transport. Finally, combining disparate approaches such as BMT and CNS-directed gene therapy can increase treatment efficacy in LSDs with severe CNS disease that are refractory to more conventional approaches.
\end{abstract}

Conclusion-The development of gene transfer vectors that mediate persistent expression in vivo, the addition of PTDs, a better understanding of lysosomal enzyme trafficking and combining different therapies provide hope that the CNS component of LSDs can be effectively treated.

\section{Keywords}

Axonal transport; Gene therapy; Lysosomal storage diseases; Neurodegenerative disorders; Viral vectors

\begin{abstract}
Lysosomal storage diseases (LSDs) represent a relatively large group of inherited metabolic disorders (1). Although individually rare, as a group these diseases occur with a frequency of approximately 1 in 6700 live births (2). The majority of LSDs are caused by the deficient activity of a single lysosomal enzyme. In the absence of this activity, macromolecules that
\end{abstract}

\footnotetext{
Correspondence MS Sands, Washington University School of Medicine, Department of Internal Medicine, Box 8007, 660 South Euclid Avenue, St. Louis, MO 63110, USA. Tel: +1 3143625494 | Fax: +1 3143629333 | msands@im.wustl.edu.

CONFLICT OF INTERESTS STATEMENT Neither MSS nor MEH have any conflicts of interest to report.
} 
are normally degraded by the enzyme in the lysosome now accumulate to high levels resulting in lysosomal distention. As lysosomal enzymes are ubiquitously expressed, the absence of activity of a single enzyme can affect multiple organ systems and result in a broad spectrum of clinical signs. One of the most devastating aspects of LSDs is the CNS involvement. CNS disease can result in developmental delay, mild-to-severe mental retardation, ataxia, seizures and profound neurodegeneration. CNS disease associated with LSDs is also one of the most difficult to treat.

Although lysosomal enzymes are intracellular proteins localized within membrane-bound vesicles, a small proportion of the mature enzymes are secreted from the cell (3). The secreted enzymes can be endocytosed and targeted to the lysosome by plasma membrane proteins - mannose-6-phosphate receptors, which are present on most cell types (4), or the mannose receptor, which is localized primarily to cells of the reticuloendothelial system (5). This secretion and endocytosis mechanism, initially referred to as 'cross-correction', forms the basis for most therapeutic approaches that have been developed for LSDs, such as bone marrow transplantation (BMT), enzyme replacement therapy (ERT) and gene therapy. BMT and ERT are relatively effective at treating the systemic disease. However, while BMT appears to be effective in some disorders (6), the efficacy of ERT in treating CNS disease is still under investigation. Therefore, other, perhaps more invasive, approaches need to be developed to treat the CNS disease associated with LSDs.

Gene therapy represents a viable therapeutic option for the treatment of CNS disease due to the potential for providing a permanent source of the deficient enzyme. A number of viral gene transfer vectors based on the adenovirus, adeno-associated virus (AAV), lentivirus, and herpes virus have been delivered directly to the CNS of small and large animal models of LSD. In addition, various ex vivo approaches, protein modifications, routes of administration and combinations of disparate therapies have increased the distribution and efficacy of CNSdirected gene therapy. Results from these studies illustrate the potential of gene therapy to effectively treat the CNS disease associated with LSDs.

\section{EX VIVO GENE THERAPY FOR THE CNS}

Ex vivo gene therapy targeted to the haematopoietic system has been developed for the potential treatment of certain inherited haematological and systemic disorders. A similar approach has shown promise in treating the systemic disease associated with LSDs. Unfortunately, with only a few exceptions $(7,8)$, haematopoietic-directed ex vivo gene therapy has proven largely ineffective for the treatment of the CNS disease in LSDs. However, ex vivo gene therapy approaches have been applied to other cell types that have then been transplanted into the CNS in small animal models of LSDs. Retrovirally transduced autologous fibroblasts expressing $\beta$-glucuronidase (GUSB) reduced lysosomal storage in areas of the brain adjacent to the graft in mice with mucopolysaccharidosis (MPS) type VII (9). MPS VII is an LSD caused by a deficiency in GUSB activity (10). In the absence of GUSB activity, glycosaminoglycans (GAGs) accumulate to high levels in many tissues of the body resulting in a complex clinical disease which involves the CNS. The MPS VII mouse has been extensively characterized and has been a powerful tool for the development of novel therapeutic approaches (11-13). Decreased lysosomal storage in the 
CNS of MPS VII mice was also accomplished following the transplantation of amniotic epithelial cells (14) or bone marrow stromal cells (15) transduced with an adenoviral or retroviral vector, respectively. These studies demonstrate that ex vivo gene therapy has the potential to treat the CNS disease associated with LSDs. The efficacy of this approach may be increased with the use of both neuronal progenitor cells $(16,17)$ that have the potential to permanently integrate into the CNS, and newer gene-transfer vectors that provide persistent in vivo expression.

\section{VIRAL-MEDIATED CNS-DIRECTED GENE THERAPY}

An alternate approach to gene therapy for the CNS is the direct injection of viral gene transfer vectors into the brain parenchyma or ventricular system. Injection of early generation adenoviral vectors either into the brain parenchyma or into the ventricular system reduced lysosomal storage in the CNS in several small animal models of LSDs (18-21). Although early generation adenoviral vectors could not be used clinically due to the associated toxicity and transient expression, these early experiments effectively demonstrate proof-of-principle. However, newer helper-dependent adenoviral vectors appear to have much lower toxicity and can mediate more persistent expression in vivo (22) and, therefore, may be clinically relevant.

AAV-based gene transfer vectors represent a promising tool for the treatment of the CNS disease associated with LSDs. AAV vectors mediate long-term in vivo expression with little or no acute toxicity (23). In addition, the tropism can be dramatically altered by pseudotyping the recombinant vectors with capsids from other AAV serotypes. This has proven particularly useful in the CNS. AAV vectors pseudotyped with capsid proteins from AAV serotypes 1, 4 and 5 transduce more cells and have a much greater distribution in the brains of mice compared with the early generation AAV2 vectors $(24,25)$. It will be important to determine the distribution and transduction efficiency in larger animal models such as primates as the tropism of these pseudotyped vectors appears to differ between species (26).

Initial experiments showed that injection of an AAV2 vector expressing GUSB into the brain parenchyma resulted in levels of expression sufficient to reduce lysosomal storage throughout the brain in adult MPS VII mice $(27,28)$. Direct injection of an AAV2 vector into the CNS of newborn MPS VII mice virtually eliminated lysosomal storage in the fore-brain and prevented cognitive dysfunction as measured in the Morris water maze test (29). More recently, certain cognitive defects were reversed in adult MPS VII mice following intraventricular injections of a vector pseudotyped with the AAV4 capsid protein (30).

Histological improvements have been obtained in a relatively large number of rodent models of different LSDs following AAV-mediated CNS-directed gene therapy. Importantly, functional improvements have also been reported in other models. Mice with MPS IIIB showed significant improvements in behavioural tests such as the open field test and the elevated plus-maze, which measure anxiety, following CNS-directed AAV-mediated gene therapy (31). In addition, AAV-mediated gene therapy significantly improved the motor 
function and seizure phenotype in mice with infantile neuronal ceroid lipofuscinosis following injection into the cortex and hippocampus (32).

AAV vectors have shown promise for the treatment of the CNS disease associated with LSDs. In addition, there appears to be little or no acute toxicity associated with these vectors. However, the incidence of hepatocellular carcinoma was significantly increased in several long-term mouse studies following systemic administration of AAV vectors $(33,34)$. In one case, the AAV vector genome integrated within a $6 \mathrm{~kb}$ region of mouse chromosome 12 in the tumours but not in normal-appearing liver tissue (35). Although there may be longterm hepatic toxicity associated with the systemic administration of AAV vectors, there have been no reports yet describing any long-term CNS toxicity. However, a systematic analysis of long-term CNS toxicity associated with intracranial administration of AAV vectors has not been performed.

Another class of viral gene transfer vector that has shown promise for CNS applications is based on recombinant lentiviruses. Both human immunodeficiency virus (HIV)- (36) and feline immunodeficiency virus (FIV)-based (37) gene transfer vectors pseudotyped with the vesicular stomatitis virus glycoprotein envelope efficiently transduced cells in the brain and mediated persistent expression. Delivery of an HIV-based vector reduced lysosomal storage in the brains of MPS VII mice (38). This positive response following CNS-directed, lentiviral-mediated gene transfer was not limited to the mouse model of MPS VII; direct delivery of an HIV-based lentiviral vector into the CNS of the mouse model of metachromatic leukodystrophy also reduced storage and improved cognitive function (39). Both histological and cognitive defects were reversed in the murine model of MPS VII following FIV-mediated CNS-directed gene therapy (40).

Finally, neurotrophic viruses such as the herpes virus have shown promise for the treatment of the CNS component of LSDs. Although not as well developed as the AAV or lentiviral vectors, recombinant herpes virus-based vectors have been shown to deliver therapeutic levels of enzyme to the CNS of MPS VII mice $(41,42)$.

\section{CNS-DIRECTED GENE THERAPY IN LARGE ANIMAL MODELS OF LSDS}

The results of CNS-directed gene therapy in small animal models of LSDs are encouraging. However, it is not clear if these approaches can be translated to the clinic as a human brain is several orders of magnitude larger than a mouse brain. Fortunately, large animal models of LSDs are available that can be used to determine if the techniques developed in rodent models can be scaled to a more appropriately sized organism. Young (3-5-month-old) dogs with MPS I received two injections in each cerebral hemisphere of an AAV5 vector expressing $\mathrm{a}$-L-iduronidase (IDUA) and their brains were then analysed biochemically and histologically (43). The vector genome and IDUA activity were detected near the injection sites and lysosomal storage was reduced in relatively large regions of the brain that extended beyond biochemically detectable enzyme activity. In a similar study, cats with amannosidosis received six injections of an AAV1 vector in each cerebral hemisphere and two injections into the cerebellum (26). Similar to the studies in the MPS I dogs, the reduction in lysosomal storage was widespread and extended well beyond the injection sites. 
Of particular importance in this study was the demonstration that the clinical neurological signs of disease (tremor, ataxia, hypermetria) were dramatically reduced in the treated cats compared with untreated animals. Although it may take more injections to effectively treat the CNS disease in humans with LSDs, these data suggest that this direct gene therapy approach is feasible.

\section{ENHANCED DELIVERY OF LYSOSOMAL ENZYMES TO THE CNS}

It is clear that CNS-directed gene therapy can be effective at reducing the histological lesions and improving neurological function in certain small and large animal models of LSDs. However, the efficacy would likely be increased, and the number of injection sites reduced if the vector or enzyme could diffuse more extensively throughout the brain. As mentioned above, AAV vectors pseudotyped with AAV1 or AAV5 capsid proteins diffused more extensively throughout the brains of mice than those pseudotyped with AAV2. Several groups have also modified the lysosomal enzymes themselves to increase the distribution in the brain. The addition of the 11 amino acid protein transduction domain from the HIV TAT protein to the C terminus of GUSB, greatly increased the distribution of the enzyme following direct intracranial injection of a gene transfer vector (44). Importantly, the modified enzyme not only diffused further through the brain, but a significant proportion of it must have been properly targeted to the lysosome as lysosomal storage was reduced in a much greater region of the brain compared with that observed following injection of the native protein. Similarly, the addition of sequences for enhanced secretion (Igא) and uptake (HIV TAT) increased the effective distribution of GUSB in the CNS of MPS VII mice (45). Although these protein modifications increase the efficacy of enzyme delivery in the experimental setting, it is possible that they may be highly immunogenic and, therefore, less efficacious in patients. Clearly, more research is needed to evaluate the immunological impact of these modifications.

Although direct intracranial injection of a viral gene transfer vector is effective at reducing lysosomal storage in the CNS and improving cognitive function, less invasive approaches would be preferable. One way to accomplish this would be to take advantage of axonal pathways within the brain that could be used to deliver enzyme more extensively with fewer injection sites. It has been shown that GUSB can be transported axonally both retrograde and anterograde following direct intracranial delivery of a viral gene transfer vector (46). Therefore, by injecting certain nuclei that have projections to many regions of the brain it might be possible to deliver enzyme more efficiently throughout the brain, effectively reducing the number of injection sites.

In addition to neuronal pathways within the brain, delivery of enzyme or vector to the brain from more external sites is also possible. For example, intrathecal injection of an AAV vector into newborn mice with MPS I or MPS VII delivered sufficient enzyme to the CNS to reduce lysosomal storage in multiple regions of the brain $(47,48)$. While this approach may not supply enough enzyme to correct the entire brain, the number of direct intracranial injections required for effective treatment would likely be reduced. Lysosomal enzymes can also be delivered to the brain through other routes. In a study designed to determine the effectiveness of eye-directed (intravitreal) gene therapy for the treatment of the retinal 
disease associated with murine MPS VII, GUSB was transported through the optic nerve from the eye into the brain (49). Lysosomal storage was reduced in the optic tracts and in non-visual regions around the optic tracts. Interestingly, these data also suggest that lysosomal enzymes can be transported trans-synaptically as lysosomal storage was reduced in regions of the visual cortex that receive signals post-synaptically. Anterograde axonal transport of the lysosomal enzyme palmitoyl protein thioesterase 1 was also observed in mice following intravitreal injection of an AAV vector (50). This result suggests that anterograde axonal transport is not limited to GUSB and may be a common feature of all lysosomal enzymes. Although anterograde axonal transport of lysosomal enzymes clearly occurs in mice, it is not clear if the same mechanisms are present in larger mammals. We show here that GUSB can be transported axonally from the eye to the brain in the canine model of MPS VII following intravitreal injection of an AAV vector (Fig. 1).

By combining vectors that are widely distributed throughout the brain together with enzyme modifications that further increase distribution, and exploiting neuronal pathways to deliver enzyme to specific regions of the brain, one can envision that CNS disease could be effectively treated even in humans. These techniques could also lead to approaches that are less invasive and more effective.

\section{COMBINATION THERAPY}

Although LSDs are simple monogenic disorders, clinically these diseases are very complex. This complexity is also observed in the CNS. In addition to the accumulation of stored substrate in many cell types of the brain, neurodegeneration, demyelination and inflammation are abnormalities commonly associated with LSDs. Given this complexity, it may not be surprising that the focal high levels of enzyme accompanied by widespread low levels of enzyme achieved with gene therapy might not completely treat the CNS dysfunction in certain LSDs. An excellent example of this is in the murine model of globoid cell leukodystrophy (GLD, Krabbe disease). Direct intracranial injections of adenoviral, AAV2, AAV1 or AAV5 vectors resulted in very high levels of activity (as much as 25-fold greater than normal) of the enzyme that is deficient in this disease, galactocerebrosidase (GALC) (51-53). In several other murine models, levels in the CNS less than this were sufficient to virtually eliminate lysosomal storage material and improve cognitive function $(29,40,54)$. Although the GALC activity resulted in statistically significant improvements in lifespan, the actual increase was only 10-20 days. Given the success in other models of LSD, this modest increase in lifespan was very disappointing. In GLD, simply supplying high levels of enzyme was not sufficient to correct the disease. Therefore, other strategies must be explored.

One strategy would be to target different aspects of the CNS disease in an attempt to enhance the efficacy of viral-mediated gene therapy. The concept of combining disparate therapies to target different aspects of the diseases has been tested using BMT and ERT in the murine model of MPS VII (55), and BMT and substrate reduction therapy in the murine model of Sandhoff disease (56). In each case, the efficacy was increased by combining therapies, and in Sandhoff disease the therapies were not simply additive but were synergistic. Therefore, mice with GLD were injected intracranially with an AAV5 vector on 
day 1-3 of life, and later the same day they underwent BMT (57). Untreated, BMT alonetreated and AAV5 alone-treated GLD mice had mean lifespans of 38, 44 and 55 days, respectively. In contrast, GLD mice that received the combination treatment had an average lifespan of approximately 105 days. Clearly, there was a dramatic synergy between these two disparate forms of therapy. Combining different therapeutic strategies may increase their efficacy in other forms of LSD.

\section{CONCLUSION}

In summary, the prospects of treating one of the most devastating aspects of LSDs, the CNS disease, appear high. However, research in small and large animal models of LSDs is still required to determine the most efficacious and least invasive combinations of gene transfer method, route of delivery, protein modification and secondary therapies. Effective CNS therapy coupled with systemic treatment will greatly enhance the quality of life for children and families with these disorders.

\section{ACKNOWLEDGEMENTS}

This work was supported in part by grants from the National Institutes of Health to MSS (DK57586) and MEH (DK54481). The experiments in the canine model of MPS VII were approved by the Institutional Animal Care and Use Committee at the University of Pennsylvania.

\section{References}

1. Neufeld EF. Lysosomal storage diseases. Annu Rev Biochem. 1991; 60:257-80. [PubMed: 1883197]

2. Meikle PJ, Hopwood JJ, Clague AE, Carey WF. Prevalence of lysosomal storage disorders. JAMA. 1999; 281:249-54. [PubMed: 9918480]

3. Neufeld EF, Fratantoni JC. Inborn errors of mucopolysaccharide metabolism. Science. 1970; 169:141-6. [PubMed: 4246678]

4. Kornfeld S. Structure and function of the mannose 6-phosphate/insulin-like growth factor II receptors. Annu Rev Biochem. 1992; 61:307-30. [PubMed: 1323236]

5. Achord DT, Brot FE, Bell CE, Sly WS. Human beta-glucuronidase: in vivo clearance and in vitro uptake by a glycoprotein recognition system on reticuloendothelial cells. Cell. 1978; 15:269-78. [PubMed: 699046]

6. Krivit, W. Stem cell bone marrow transplantation in patients with metabolic storage diseases. In: Barnes, LA.; DeVivo, DC.; Kaback, MM.; Morrow, GI.; Rudolph, AM.; Tunnessen, WWJ., editors. Advances in pediatrics. Mosby; Philadephia: 2002. p. 359-78.

7. Walkley SU, Thrall MA, Dobrenis K, Huang M, March PA, Siegal DA, et al. Bone marrow transplantation corrects the enzyme defect in neurons of the central nervous system in a lysosomal storage disease. Proc Natl Acad Sci USA. 1994; 91:2970-4. [PubMed: 8159689]

8. Biffi A, De Palma M, Quattrini A, Del Carro U, Amadio S, Visigalli I, et al. Correction of metachromatic leukodystrophy in the mouse model by transplantation of genetically modified hematopoietic stem cells. J Clin Invest. 2004; 113:1118-29. [PubMed: 15085191]

9. Taylor RM, Wolfe JH. Decreased lysosomal storage in the adult MPS VII mouse brain in the vicinity of grafts of retroviral vector-corrected fibroblasts secreting high levels of betaglucuronidase. Nat Med. 1997; 3:771-4. [PubMed: 9212105]

10. Sly WS, Quinton BA, McAlister WH, Rimoin DL. Beta glucuronidase deficiency: report of clinical, radiologic, and biochemical features of a new mucopolysaccharidosis. J Pediatr. 1973; 82:249-57. [PubMed: 4265197] 
11. Birkenmeier EH, Davisson MT, Beamer WG, Ganschow RE, Vogler CA, Gwynn B, et al. Murine mucopolysaccharidosis type VII. Characterization of a mouse with beta-glucuronidase deficiency. J Clin Invest. 1989; 83:1258-66. [PubMed: 2495302]

12. Sands MS, Birkenmeier EH. A single-base-pair deletion in the beta-glucuronidase gene accounts for the phenotype of murine mucopolysaccharidosis type VII. Proc Natl Acad Sci USA. 1993; 90:6567-71. [PubMed: 8101990]

13. Wolfe, JH.; Sands, MS. Murine mucopolysaccharidosis type VII: a model system for somatic gene therapy of the central nervous system. In: Lowenstein, P.; Enquist, L., editors. Gene transfer into neurones, towards gene therapy of neurological disorders. J Wiley and Sons; Essex: 1996. p. 263-74.

14. Kosuga M, Sasaki K, Tanabe A, Li XK, Okawa H, Ogino I, et al. Engraftment of genetically engineered amniotic epithelial cells corrects lysosomal storage in multiple areas of the brain in mucopolysaccharidosis type VII mice. Mol Ther. 2001; 3:139-48. [PubMed: 11237670]

15. Sakurai K, Iizuka S, Shen JS, Meng XL, Mori T, Umezawa A, et al. Brain transplantation of genetically modified bone marrow stromal cells corrects CNS pathology and cognitive function in MPS VII mice. Gene Ther. 2004; 11:1475-81. [PubMed: 15295619]

16. Snyder EY, Taylor RM, Wolfe JH. Neural progenitor cell engraftment corrects lysosomal storage throughout the MPS VII mouse brain. Nature. 1995; 374:367-70. [PubMed: 7885477]

17. Buchet D, Serguera C, Zennou V, Charneau P, Mallet J. Long-term expression of betaglucuronidase by genetically modified human neural progenitor cells grafted into the mouse central nervous system. Mol Cell Neurosci. 2002; 19:389-401. [PubMed: 11906211]

18. Ohashi T, Watabe K, Uehara K, Sly WS, Vogler C, Eto Y. Adenovirus-mediated gene transfer and expression of human beta-glucuronidase gene in the liver, spleen, and central nervous system in mucopolysaccharidosis type VII mice. Proc Natl Acad Sci USA. 1997; 94:1287-92. [PubMed: 9037045]

19. Ghodsi A, Stein C, Derksen T, Yang G, Anderson RD, Davidson BL. Extensive betaglucuronidase activity in murine central nervous system after adenovirus-mediated gene transfer to brain. Hum Gene Ther. 1998; 9:2331-40. [PubMed: 9829532]

20. Bourgoin C, Emiliani C, Kremer EJ, Gelot A, Tancini B, Gravel RA, et al. Widespread distribution of beta-hexosaminidase activity in the brain of a Sandhoff mouse model after coinjection of adenoviral vector and mannitol. Gene Ther. 2003; 10:1841-9. [PubMed: 12960974]

21. Virta S, Rapola J, Jalanko A, Laine M. Use of nonviral promoters in adenovirus-mediated gene therapy: reduction of lysosomal storage in the aspartylglucosaminuria mouse. J Gene Med. 2006; 8:699-706. [PubMed: 16518877]

22. Kim IH, Jozkowicz A, Piedra PA, Oka K, Chan L. Lifetime correction of genetic deficiency in mice with a single injection of helper-dependent adenoviral vector. Proc Natl Acad Sci USA. 2001; 98:13282-7. [PubMed: 11687662]

23. Monahan PE, Samulski RJ. AAV vectors: is clinical success on the horizon? Gene Ther. 2000; 7:24-30. [PubMed: 10680012]

24. Davidson BL, Stein CS, Heth JA, Martins I, Kotin RM, Derksen TA, et al. Recombinant adenoassociated virus type 2, 4, and 5 vectors: transduction of variant cell types and regions in the mammalian central nervous system. Proc Natl Acad Sci USA. 2000; 97:3428-32. [PubMed: 10688913]

25. Burger C, Gorbatyuk OS, Velardo MJ, Peden CS, Williams P, Zolotukhin S, et al. Recombinant AAV viral vectors pseudotyped with viral capsids from serotypes 1,2, and 5 display differential efficiency and cell tropism after delivery to different regions of the central nervous system. Mol Ther. 2004; 10:302-17. [PubMed: 15294177]

26. Vite CH, McGowan JC, Niogi SN, Passini MA, Drobatz KJ, Haskins ME, et al. Effective gene therapy for an inherited CNS disease in a large animal model. Ann Neurol. 2005; 57:355-64. [PubMed: 15732095]

27. Skorupa AF, Fisher KJ, Wilson JM, Parente MK, Wolfe JH. Sustained production of betaglucuronidase from localized sites after AAV vector gene transfer results in widespread distribution of enzyme and reversal of lysosomal storage lesions in a large volume of brain in mucopolysaccharidosis VII mice. Exp Neurol. 1999; 160:17-27. [PubMed: 10630187] 
28. Bosch A, Perret E, Desmaris N, Heard JM. Long-term and significant correction of brain lesions in adult mucopolysaccharidosis type VII mice using recombinant AAV vectors. Mol Ther. 2000; 1:63-70. [PubMed: 10933913]

29. Frisella WA, O'Connor LH, Vogler CA, Roberts M, Walkley S, Levy B, et al. Intracranial injection of recombinant adeno-associated virus improves cognitive function in a murine model of mucopolysaccharidosis type VII. Mol Ther. 2001; 3:351-8. [PubMed: 11273777]

30. Liu G, Martins I, Wemmie JA, Chiorini JA, Davidson BL. Functional correction of CNS phenotypes in a lysosomal storage disease model using adeno-associated virus type 4 vectors. J Neurosci. 2005; 25:9321-7. [PubMed: 16221840]

31. Cressant A, Desmaris N, Verot L, Brejot T, Froissart R, Vanier MT, et al. Improved behavior and neuropathology in the mouse model of Sanfilippo type IIIB disease after adeno-associated virusmediated gene transfer in the striatum. J Neurosci. 2004; 24:10229-39. [PubMed: 15537895]

32. Griffey MA, Wozniak D, Wong M, Bible E, Johnson K, Rothman SM, et al. CNS-directed AAV2mediated gene therapy ameliorates functional deficits in a murine model of infantile neuronal ceroid lipofuscinosis. Mol Ther. 2006; 13:538-47. [PubMed: 16364693]

33. Donsante A, Vogler C, Muzyczka N, Crawford JM, Barker J, Flotte T, et al. Observed incidence of tumorigenesis in long-term rodent studies of rAAV vectors. Gene Ther. 2001; 8:1343-6. [PubMed: 11571571]

34. Bell P, Moscioni AD, McCarter RJ, Wu D, Gao G, Hoang A, et al. Analysis of tumors arising in male B6C3F1 mice with and without AAV vector delivery to liver. Mol Ther. 2006; 14:34-44. [PubMed: 16682254]

35. Donsante A, Miller D, Li Y, Vogler C, Brunt E, Russell D, et al. AAV vector integration sites in mouse hepatocellular carcinoma. Science. 2007; 317:477. [PubMed: 17656716]

36. Naldini L, Blomer U, Gallay P, Ory D, Mulligan R, Gage FH, et al. In vivo gene delivery and stable transduction of nondividing cells by a lentiviral vector. Science. 1996; 272:263-7. [PubMed: 8602510]

37. Poeschla EM, Wong-Staal F, Looney DJ. Efficient transduction of nondividing human cells by feline immunodeficiency virus lentiviral vectors. Nat Med. 1998; 4:354-7. [PubMed: 9500613]

38. Bosch A, Perret E, Desmaris N, Trono D, Heard JM. Reversal of pathology in the entire brain of mucopolysaccharidosis type VII mice after lentivirus-mediated gene transfer. Hum Gene Ther. 2000; 11:1139-50. [PubMed: 10834616]

39. Gieselmann V. Metachromatic leukodystrophy: genetics, pathogenesis and therapeutic options. Acta Paediatrica. 2008; 97(Suppl 457):15-21. [PubMed: 18339182]

40. Brooks AI, Stein CS, Hughes SM, Heth J, McCray PM Jr, Sauter SL, et al. Functional correction of established central nervous system deficits in an animal model of lysosomal storage disease with feline immunodeficiency virus-based vectors. Proc Natl Acad Sci USA. 2002; 99:6216-21. [PubMed: 11959904]

41. Wolfe JH, Deshmane SL, Fraser NW. Herpesvirus vector gene transfer and expression of betaglucuronidase in the central nervous system of MPS VII mice. Nat Genet. 1992; 1:379-84. [PubMed: 1338772]

42. Zhu J, Kang W, Wolfe JH, Fraser NW. Significantly increased expression of beta-glucuronidase in the central nervous system of mucopolysaccharidosis type VII mice from the latency-associated transcript promoter in a nonpathogenic herpes simplex virus type 1 vector. Mol Ther. 2000; $2: 82$ 94. [PubMed: 10899831]

43. Ciron C, Desmaris N, Colle MA, Raoul S, Joussemet B, Verot L, et al. Gene therapy of the brain in the dog model of Hurler's syndrome. Ann Neurol. 2006; 60:204-13. [PubMed: 16718701]

44. Xia H, Mao Q, Davidson BL. The HIV Tat protein transduction domain improves the biodistribution of beta-gluc-uronidase expressed from recombinant viral vectors. Nat Biotechnol. 2001; 19:640-4. [PubMed: 11433275]

45. Elliger SS, Elliger CA, Lang C, Watson GL. Enhanced secretion and uptake of beta-glucuronidase improves adeno-associated viral-mediated gene therapy of mucopolysaccharidosis type VII mice. Mol Ther. 2002; 5:617-26. [PubMed: 11991753] 
46. Passini MA, Lee EB, Heuer GG, Wolfe JH. Distribution of a lysosomal enzyme in the adult brain by axonal transport and by cells of the rostral migratory stream. J Neurosci. 2002; 22:6437-46. [PubMed: 12151523]

47. Watson G, Bastacky J, Belichenko P, Buddhikot M, Jungles S, Vellard M, et al. Intrathecal administration of AAV vectors for the treatment of lysosomal storage in the brains of MPS I mice. Gene Ther. 2006; 13:917-25. [PubMed: 16482204]

48. Elliger SS, Elliger CA, Aguilar CP, Raju NR, Watson GL. Elimination of lysosomal storage in brains of MPS VII mice treated by intrathecal administration of an adeno-associated virus vector. Gene Ther. 1999; 6:1175-8. [PubMed: 10455422]

49. Hennig AK, Levy B, Ogilvie JM, Vogler CA, Galvin N, Bassnett S, et al. Intravitreal gene therapy reduces lysosomal storage in specific areas of the CNS in mucopolysaccharidosis VII mice. J Neurosci. 2003; 23:3302-7. [PubMed: 12716937]

50. Griffey M, Macauley SL, Ogilvie JM, Sands MS. AAV2-mediated ocular gene therapy for infantile neuronal ceroid lipofuscinosis. Mol Ther. 2005; 12:413-21. [PubMed: 15979943]

51. Shen JS, Watabe K, Ohashi T, Eto Y. Intraventricular administration of recombinant adenovirus to neonatal twitcher mouse leads to clinicopathological improvements. Gene Ther. 2001; 8:1081-7. [PubMed: 11526455]

52. Rafi MA, Zhi Rao H, Passini MA, Curtis M, Vanier MT, Zaka M, et al. AAV-mediated expression of galactocerebrosidase in brain results in attenuated symptoms and extended life span in murine models of globoid cell leukodystrophy. Mol Ther. 2005; 11:734-44. [PubMed: 15851012]

53. Lin D, Fantz CR, Levy B, Rafi MA, Vogler C, Wenger DA, et al. AAV2/5 vector expressing galactocerebrosidase ameliorates CNS disease in the murine model of globoid-cell leukodystrophy more efficiently than AAV2. Mol Ther. 2005; 12:422-30. [PubMed: 15996520]

54. Consiglio A, Quattrini A, Martino S, Bensadoun JC, Dolcetta D, Trojani A, et al. In vivo gene therapy of metachromatic leukodystrophy by lentiviral vectors: correction of neuropathology and protection against learning impairments in affected mice. Nat Med. 2001; 7:310-16. [PubMed: 11231629]

55. Sands MS, Vogler C, Torrey A, Levy B, Gwynn B, Grubb J, et al. Murine mucopolysaccharidosis type VII: long term therapeutic effects of enzyme replacement and enzyme replacement followed by bone marrow transplantation. J Clin Invest. 1997; 99:1596-605. [PubMed: 9120003]

56. Jeyakumar M, Norflus F, Tifft CJ, Cortina-Borja M, Butters TD, Proia RL, et al. Enhanced survival in Sandhoff disease mice receiving a combination of substrate deprivation therapy and bone marrow transplantation. Blood. 2001; 97:327-9. [PubMed: 11133779]

57. Lin D, Donsante A, Macauley SL, Levy B, Vogler C, Sands MS. Central nervous system-directed AAV2/5-mediated gene therapy synergizes with bone marrow transplantation in the murine model of globoid-cell leukodystrophy. Mol Ther. 2006; 15:44-52. [PubMed: 17164774]

58. Daly TM, Vogler C, Levy B, Haskins ME, Sands MS. Neonatal gene transfer leads to widespread correction of pathology in a murine model of lysosomal storage disease. Proc Natl Acad Sci USA. 1999; 96:2296-300. [PubMed: 10051635] 


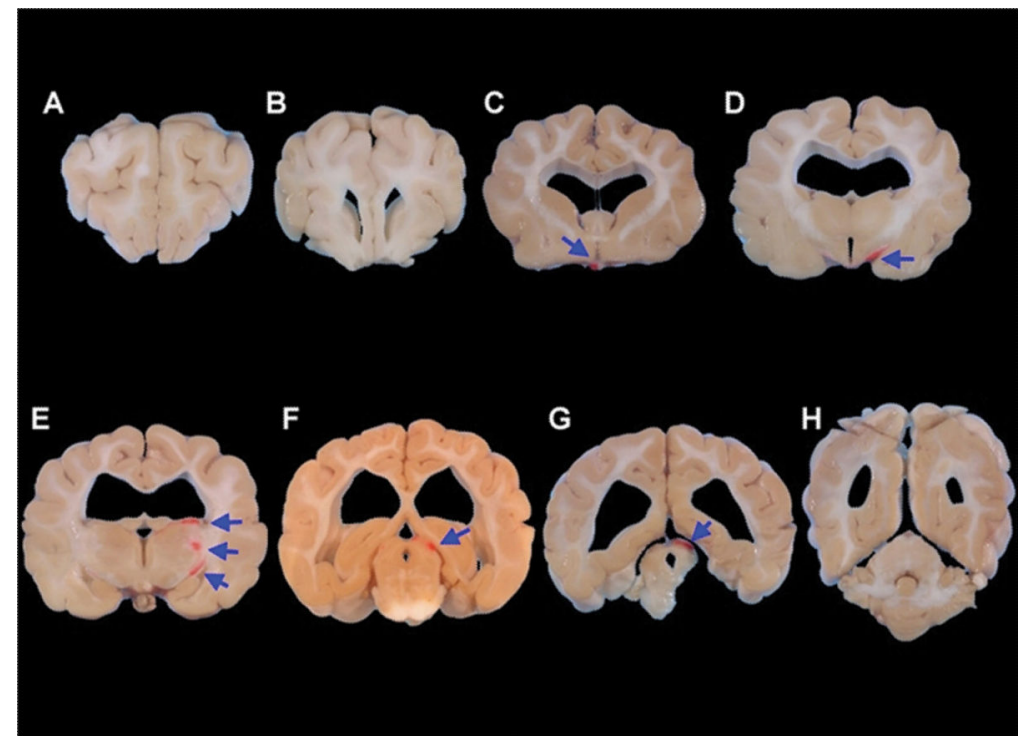

Figure 1.

Anterograde axonal transport of $\beta$-glucuronidase (GUSB) in canine mucopolysaccharidosis type VII (MPS VII). One-month-old dogs with MPS VII were injected intravitreally with approximately $7 \times 10^{8}$ infectious units of the same AAV2 vector expressing human GUSB (AAV-GUSB) that was used in previous experiments (58). The animal shown received a single injection in the left eye and was examined 6 months post injection. Robust GUSB expression was observed in the retina of the injected animal (data not shown). Coronal sections (5-8 mm thick) of the brain from rostral $(A)$ to caudal $(\mathrm{H})$ were stained histochemically (13) for GUSB activity. GUSB activity (red stain, blue arrows) was observed in the optic nerve (C) and through the visual tracts of the brain (sections D-G). 